\title{
USING NURSERY RHYMES TO ENHANCE VOCABULARY AMONG YOUNG ENGLISH LEARNERS IN INDONESIA
}

\author{
Ipung Sri Purwanti Hery \\ Sekolah Tinggi Ilmu Ekonomi AUB Surakarta, Indonesia \\ Imran Arshad \\ Barrett Hodgson University, Pakistan
}

\begin{abstract}
This research is being conducted to examine and explain the results of using nursery rhymes in improving vocabulary skills among young English learners in Indonesia. This study focuses on whether the use of nursery rhymes in English teaching will significantly improve vocabulary mastery among Indonesian elementary learners. Two English teachers and eighty students from two elementary schools in Depok-Sleman, Yogyakarta, Indonesia who are in third grade and aged between eight and nine years participated in this report. The theoretical basis of this current study is based on the concrete theory of learning by Ausubel, the theory of social constructivism by Vygotsky and the theory of second-language acquisition by Krashen. This research employs the quasi-experimental approach, the experimental group was taught English using nursery rhymes and the control group was taught over a span of eight weeks using traditional method. Pre-test and post-test instruments were used to collect data for the analysis. The results suggest that the use of nursery rhymes substantially improved average vocabulary scores for the students. Students from the experimental group also performed significantly better in matching the vocabulary with the correct image, matching the English vocabulary with its synonyms in Bahasa Indonesia and filling in the blanks with the right choice of English vocabulary compared to their counterparts in the control group. This study asserts that the use of nursery rhymes can significantly enhance the awareness of vocabulary among students. This research also has significant pedagogical implications and developments on the use of nursery rhymes to teach English vocabulary. Hopefully the Indonesian Ministry of Education and Teacher Education Division will train teachers to use nursery rhymes to develop English vocabulary for young learners.
\end{abstract}

Key words: Nursery rhymes, Vocabulary, Young learners, English language teaching, Conventional method. 
Cite this Article: Ipung Sri Purwanti Hery and Imran Arshad, Using Nursery Rhymes to Enhance Vocabulary among Young English Learners in Indonesia, International Journal of Management, 11(9), 2020, pp. 212-226. http://iaeme.com/Home/issue/IJM?Volume $=11 \&$ Issue $=9$

\section{INTRODUCTION}

Vocabulary comprehension is key to second language learning. Unfortunately, there isn't a sufficient degree of vocabulary mastery among young Indonesian learners. Several studies suggest that the skills and level of communication in English of Indonesian students are not adequate (Arzal \& Tanipu, 2014; Prihatin, 2012). Early childhood is a stage where fantasy and imagination grow. For this reason, it is only natural that the education is based on developing the imagination of children at this point. To do this, children need to be introduced to enjoyable learning and creative methods in teaching that actively involve children in the learning process such as cheering, playing and singing, so education should not be boring. This is especially important even during the early childhood stage, since literacy shapes the aspirations and ambitions of a child in life after all (Yusuf \& Enesi, 2012). Likewise, the concern of an instructor is not always focused on how effective language teaching can be, but on how to provide the teaching and learning to the students in a fun way. Preparation for English language instruction is therefore necessary. In this regard, one of the most critical factors involved in language teaching is an efficient and yet enjoyable process and techniques (Er, 2014).

In Indonesia, because of globalisation, young generations are challenged to engage in the global markets and leverage the economic opportunities. Considering that English is a twofold strategy that acts as a tool not only for global communication but also for the preservation of the national cultural heritage, it becomes imperative that the English language should be in command among Indonesian children (Musthafa, 2010; Sikki, Rahman, Hamra, \& Noni, 2013; Yuwono \& Harbon, 2010). According to Ara (2009), elementary level second language learners reacted very well when exposed to nursery rhymes because children are instinctively drawn to the repeated rhythms. While it may be difficult for younger second language learners to remember and articulate the phrases in a foreign language, they may later become more eloquent until they have been able to understand and memorise the nursery rhymes. For eg, the rhyme "head, shoulders, knees, and toes" offers more entertaining experience as children get absorbed not only in the rhythm and physical activity, but also developed their vocabulary in terms of the different parts of the body. As children subconsciously learn the sounds of languages and therefore are able to intuitively recognize the words and sentences, it is observed that children learn and remember more effectively through the constant repetition of listening and recapitulation of nursery rhymes. After learning the words that rhymed, the children are later encouraged to use the same rhyming scheme to enunciate and phone new words (Shwetha, 2013). This study explores the influence of nursery rhymes in enhancing vocabulary among young Indonesian English learners, through the use of quasi-experimental research design. This study further investigates whether the use of nursery rhymes in English teaching is capable of enriching vocabulary among young second language learners in Indonesia, especially in their ability to match the vocabulary with the correct image, matching English vocabulary with its synonyms in Bahasa Indonesia and filling in the blanks with the right choice of English vocabulary. 


\section{PROBLEM STATEMENT}

Language learning happens when actual signals are heard, and the acquirer is not 'on the defensive' (Krashen, 1981). Nursery rhymes with its essence of fun and enjoyment can be a resourceful learning material to improve the vocabulary of the young English learners.

Indonesia needs to boost the teaching and learning quality in order to succeed in today's globalised world. Thus, like any other Asian nation, Indonesia, too, is undergoing a series of educational reforms to restructure the curriculum and pedagogy in English language teaching and learning. The Ministry of Education and Culture in Indonesia, having realised the importance of English as a medium of communication, is beginning to emphasise the use of English with the aim of improving English communication skills among students (Indonesia Ministry of Education and Culture 2013). In Indonesia the English language teaching has gained significant attention. Subsequently, the definition of English demands that language be taught in both junior and senior high schools as a compulsory subject. Since 1994 English is taught as an elective subject in the Elementary Schools due to the introduction of the 1993 curriculum (Arzal \& Tanipu, 2014). While the 2013 curriculum has stirred the wrath of the private and state-regulated education sector, removing English at the elementary level and replacing it with additional hours of Indonesian language, both educational experts and the public argued that the new system of subjects would only benefit Indonesian students, rendering them less competitive at the international level. Based on the Education First Index (2013), Indonesia 's rating for the English Proficiency Index has improved significantly; Indonesia was ranked 34th out of 54 countries, a very low proficiency index for 2011. However, in 2013 it improved and was ranked 25th among a total of 54 countries with a moderate index of skills. However, the ranking plummeted among 63 other countries to 28th in 2015 (English First, 2015). Figure below shows the details.

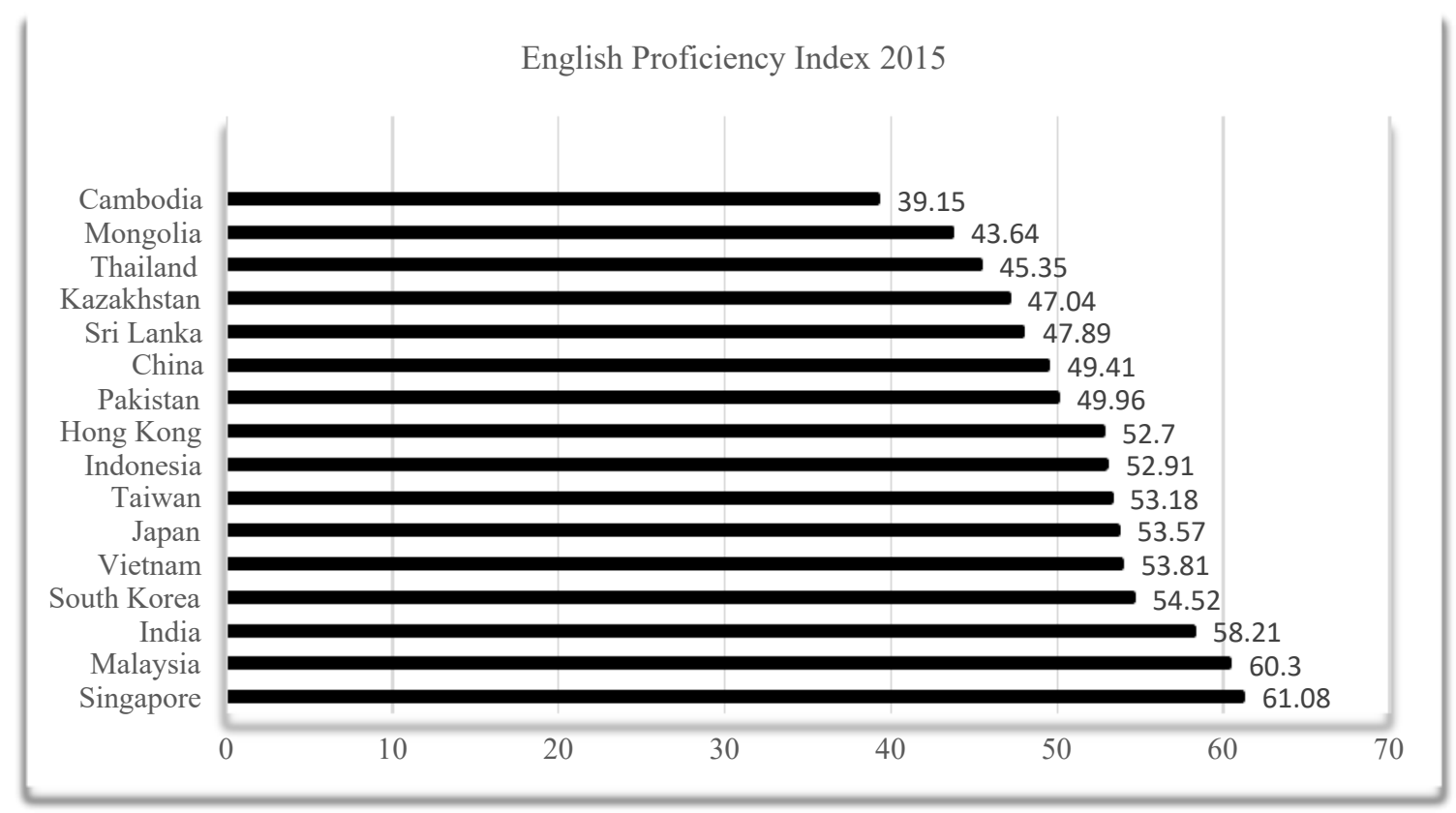

Figure 1 English First: English Proficiency Index 2015

Despite the reformation of teaching pedagogies, there are opposing arguments that in line with the pedagogical reformations, the use of English language does not dramatically change. Researchers found unsatisfactory evidence showing a lack of development in the English 
skills and communication skills of the students (Arzal \& Tanipu, 2014; Education First, 2013; English First, 2015; Prihatin, 2012; Seargeant \& Erling, 2011).

Hence the importance of learning a second language seems to be a trivial field of study in view of that. While research has received significant attention in recent years in the field of second language learning, the effort to encourage the learning of a second language in schools has nevertheless been distressingly imperceptible. Research conducted by Horst (2014) in Indonesia found that the traditional English-language input does not support the acquisition of a higher vocabulary level. Although students may pass their English test, their communication skills can nonetheless be unplausible. The decision to incorporate English into the elementary school is seen as a way of creating an English-savvy community. It is a good step because it is hypothesised that the earlier one studies English, the more time one can have to deal with it and the better the skill that would be beneficial to international businesses at the end of the day (Kurniasih, 2011; Arzal \& Tanipu, 2014), the more learning English can be a means of learning other subjects, such as mathematics, science, social studies, etc.

In Indonesia, numerous studies have been conducted to assess the effect of songs on vocabulary acquisition among the language performance outcomes of elementary students (Intani, 2012; Lamb, 2009; Lamb \& Colemen, 2008; Sari, 2008; Sikki et al., 2013; Widyaningrum, 2011). Similarly, other studies carried out in other countries such as India where English is taught as a foreign language have shown that it is effective to use nursery rhymes to promote oral skills, interest and motivation to learn English. (Schiller, 2010; Harper, 2011; Shwetha, 2013). In Indonesia, however, research on the use of nursery rhymes to promote vocabulary learning remain scarce. None of 30 elementary schools in Yogyakarta, in a preliminary report, used nursery rhymes to boost vocabulary in English language teaching. That is why this current study aims to investigate the effect of using nursery rhymes to develop vocabulary among young learners in Indonesia.

Nearly 50 to $80 \%$ of human intelligence, awareness, and wisdom are developed in early childhood, according to Bloom (1964). Vos (2007) said all of the later-life learning was based on the information we learned in the early years. Thus, learning English vocabulary through the use of nursery rhymes is presumed to be an important means of achieving a better mastery of English vocabulary among young second language learners in Indonesia. The nature of nursery rhymes can be told as a storey and read as a poem which is fun and enjoyment. Also it can serve as an enticing dance. As Jones, B (1972) has stated, a storey telling can act as a medium for expanding imagination over the first seven years. A child needs full sensory interaction to form intelligence, knowledge and wisdom. A full body movement when the nursery rhymes were dancing offered a lot of kinaesthetic learning involving many senses.

These movements incorporate the primary reflexes which are the basis for healthy brain development. Our entire brain (brain stem, mid-brain limbic system, and cortex) develops through movements. They have done these brain-developing motions on the floor as infants. They continue to look at these trends as children and adults in a number of ways to keep their brains and bodies healthy (Cassel, 2013)

In Indonesia, by and large, many teachers are still following the traditional approach to teaching, through which they only set out to explain, ask and answer questions. Such typical method of teaching causes boredom and this also leads to apathic behaviour. Students lose interest in the language itself, as they find it hard to absorb whatever information has been provided. Internet is considered best way to teach and for interaction with others (Bhatti \& Akram, 2020; Bhatti, Bano, \& Rehman, 2019). Consequently, this study aims to fill the gap by examining the impact of using nursery rhymes to improve vocabulary acquisition among young Indonesian English learners. The acquisition of vocabulary is an essential part of language learning, because it is the focus of language. Candlin (1988) believed that 
vocabulary as the focal point of language defines the route of any language studies, considering that it is not only the organisation of the syllabuses that is specified, but also the performance assessment and the provision of appropriate learning tools. Knight (1994) found the "learning words" process to be the most important aspect of second-language acquisition.

\section{OBJECTIVES OF THE STUDY}

The goal of the study is to investigate whether the use of nursery rhymes in English teaching can significantly enhance the mastery of vocabulary by focusing specifically on matching the English vocabulary with the correct image, matching the English vocabulary with its synonyms in Bahasa Indonesia and filling in the blanks with the right choice of English vocabulary for students in the English language Four null hypotheses (Ho) are formulated using the criteria as follows:

1. There is no difference of meaning in their total vocabulary scores between Experimental Group and the Control Group.

2. There is no difference of significance in their overall scores between the Experimental Group and the Control Group in matching the English vocabulary with the correct image.

3. There is no difference of importance in their scores between the Experimental Group and the Control Group in matching English vocabulary with synonyms in Bahasa Indonesia.

4. There is no difference in meaning between the Study Group and the Control Group in their scores for filling the blanks with the correct word choice.

The second-language learning process can be very long, complex and difficult, according to Brown (2007). Second language learning is a major undertaking and has been discussed by several researchers. But the researchers chose to concentrate on three basic hypotheses for the purposes of this particular study. They are theories of Ausble's practical learning (1963), Vygotsky's theory of social constructivism (1978), and Krashen 's theory of second language acquisition (1982). Parts below outline the study context.

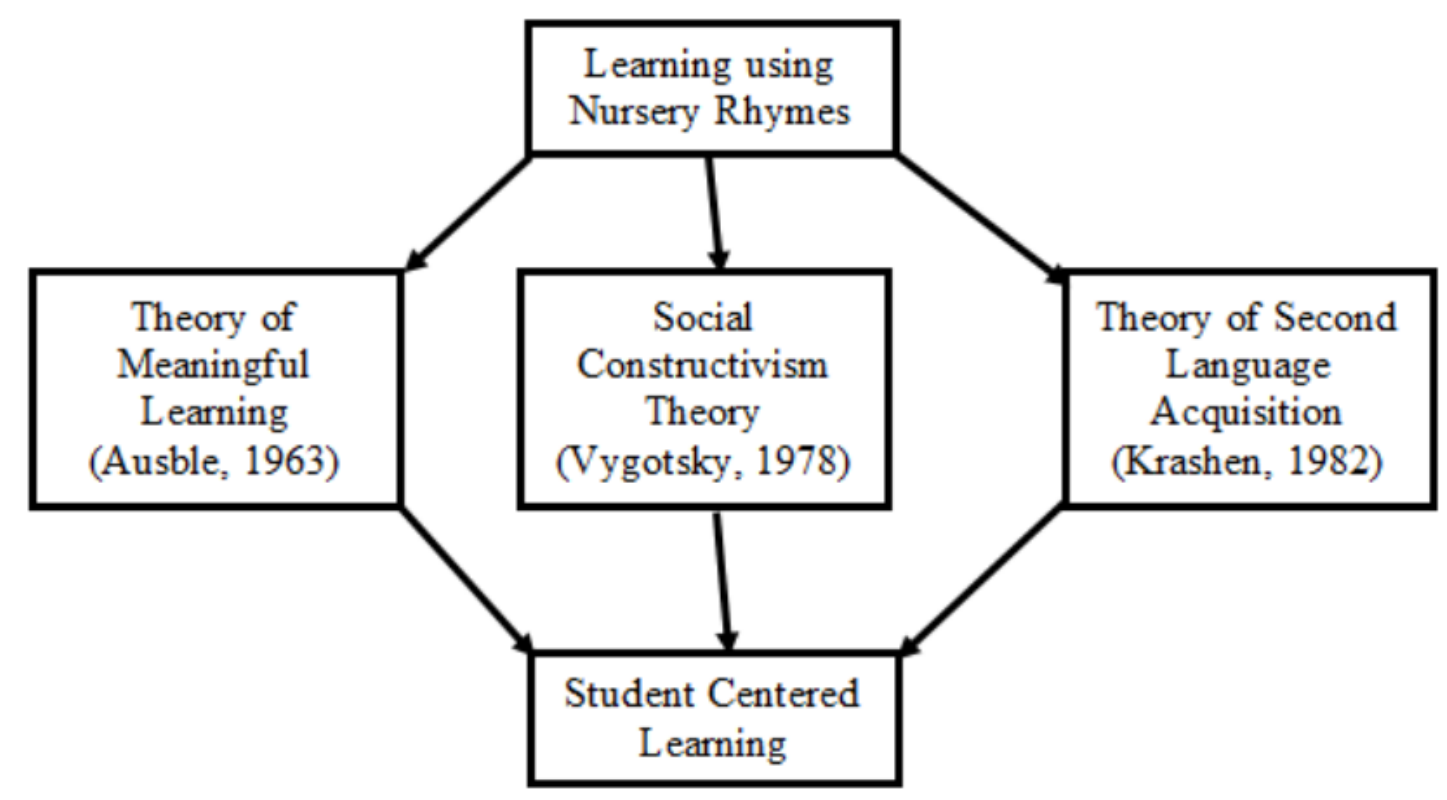

Figure 2 


\section{THEORETICAL MODEL OF THE STUDY}

\subsection{Review of Literature}

Auasubel's Theory of Meaningful Learning: Ausubel (1963) in his theory of meaningful learning views an individual's organization of knowledge as a cognitive structure. The advance organizer model of teaching founded by Ausubel is also predominantly used by teachers to model and benchmark practical teaching pedagogies. The theory of meaningful learning emphasises on:

- Meaningful material: The content of the material should be a meaningful so that second language learners can learn it in more meaningful way.

- Learner's relevant prior knowledge: Students must possess the previously established concept in an organized way so that the new learned knowledge can be easily linked with the prior knowledge.

- Learner's choice to use meaningful learning: Second language learners should exhibit a more positive attitude towards meaningful learning; this will demonstrate his/her temperament to related the newly acquired material with their cognitive structure.

Vygotsky's Theory of Social Constructivism: Vygotsky (1978) in his social constructivist theory advocate that a child learns better when assisted by adult or more competent peer. In this study students observe their teachers, interact with others and sing the nursery rhymes. Tracey and Morrow (2012) investigated how children internalize language through interaction with others, it is discovered that the social context of language or inner speech occurs when (a) children learn language through interaction with others, (b) language development is dependent on sign systems, (c) in order to learn new concepts one must be functioning in the "zone of proximal development" and (d) learning support occurs through "scaffolding"

\section{Krashen's Theory of Second Language Acquisition}

Five hypothesis are drawn based on the theory. However in this current study, only four hypothesis are employed. The Monitor Hypothesis is excluded due to its wide application in teaching interventions for adults.

\section{The Acquisition-Learning Hypothesis}

The Acquisition-Learning Hypothesis states that second language performance has two independent systems (Krashen, 1982). The first is the acquired system or acquisition, which is the product of the subconscious, like children acquiring their first language (Krashen, 1982). The second is the learned system or learning, which is a conscious process derived from formal instruction.

\section{The Natural Order Hypothesis}

The Natural Order Hypothesis is based on the findings of the research (Dulay \& Burt, 1974; Fathman, 1975; Makino, 1980 as cited in Krashen, 1987) which suggests that predictable natural order is preceded by the acquisition of grammatical structures. When target is acquisition of language, according to Krashen (1987) grammatical sequencing is rejected and the language program syllabus should not be based on the order in the studies.

\section{The Input Hypothesis}

The Input Hypothesis is an attempt by Krashen to explain how the second language acquisitions is acquired by the learners. According to this hypothesis, input must be comprehensible for language learners to retain the information (Krashen, 1982). He states that for learning to take place learners must receive interesting linguistic content which is at their 
level of competence or slightly above "comprehensible input (i+1)" (Shrum \& Glisan, 2000). Dividing language up into smaller comprehensible parts (chunking), can assist language learning (Shrum \& Glisan, 2000).

\section{The Affective Filter Hypothesis}

The Affective Filter Hypothesis states that second language acquisition is facilitated by many affective variables (Krashen, 1982). These variables are: motivation, self-confidence and anxiety. High motivation, low self-confidence and low anxiety facilitates language acquisition, whereas low motivation, low self-esteem and high anxiety raise the affective filter and create a mental block that prevents language acquisition.

\section{Importance of Vocabulary Learning}

Vocabulary is what defines reading comprehension according to Baumann, Kam'enui, and Ash (2003). Equally, vocabulary also affects the success of the students (Stahl \& Fairbanks, 1986). Vocabulary plays an significant part in second language learning. This means that it is not possible to learn vocabulary by actually engaging with the language itself. Though second language vocabulary is seen as important as reading, writing, communicating and listening. Mehring (2010) argued that knowing what and how to teach and how to make the lesson plan successful is more important, since it will ultimately help students learn. The acquisition of an extensive vocabulary is considered the most essential for successful communication (Milton, 2009; Nation, 2001). It is known in schools that children interact extensively in different languages and therefore, oral abilities in schools are diversified. But children in kindergarten have slightly lower levels of vocabulary skills relative to their older peers (Hart \& Risley, 1995). Such a gap exists and is widening even in early childhood (Biemiller \& Slonim, 2001).

\section{The use of Nursery Rhymes to Enhance Vocabulary}

Vocabulary plays a significant part in the process of teaching and studying languages. Words are not learned from a dictionary but are obtained through writing, listening, speaking, and reading. The acquisition of vocabulary knowledge does not occur instantly but is a lifelong process. Therefore, schools play an important role in gaining vocabulary skills, as the skills of the students is further enriched and strengthened by writing the knowledge of the students (Atta-Alla, 2012). Core vocabulary is also of special significance since it is an important source of language learning. Consequently, it is necessary that children in elementary schools may start learning their core vocabulary. In order to acquire core vocabulary, children or adults who are starting to learn new language need to be taught in a formal approach, using symbols and signs. The Dunst, Meter, and Hamby (2011) research that examined the relationships between phonological and print-related skills comprehension and nursery rhyme explores 15 literacy skills among a broad group of pre-schoolers. Likewise, MacLean et al. (1987) also conducted a study requiring the recitation of common nursery rhymes among young children. Meanwhile, Boudreu's (2005) research used nursery rhymes and rhyming games to test children's rhyming skill.

\section{Students' Centred Learning and Vocabulary Teaching}

In the 18th century, when home schooling was no longer practised, textbooks were used to replace school teaching, and among the many textbooks available, McGuffey Readers were among the first of which a series of books called the basal reading series. The books too integrated universal principles such as being supportive and kind to both humans and animals into the storeys. However, learning was teacher-centered in the 18th century, in which students are expected to do rote learning (Rehyner, 2003). Rehyner also stressed that a teacher's position is crucial particularly in acquiring students ' vocabulary skills. Chall (2000) 
argued that teachers are given much choice to enhance vocabulary learning for a teachercentric and curriculum-centric approach.

According to Nielsen (2003), a skill-based approach or also known as teacher-centered approach for teachers who employed the reading readiness perspective to improve literacy. Such an method is built based on a teaching instructions relational model. This method considers teaching to be the transmission of knowledge. Therefore, this approach appears to focus on the consequences and not the learning process itself.

\section{METHODOLOGY}

It is important part of every research to guide the way to obtain the objectives (Bhatti \& Rehman, 2019a, 2019b; Bhatti, Rehman, Akram, \& Shaheen, 2020).Using quantitative method, this is a quasi-experimental analysis. The sample of this current study is made up of 80 students from two elementary schools in Depok-Sleman, Yogyakarta, Indonesia (8 to 9 years old, 3rd grade). The results from the two schools are almost identical in terms of their academic performance, gender balance and school ranking. School A subjects (40 students) make up the Experimental Group while School B subjects (40 students) represent the Control Group.

This research lasted for ten weeks. Both the Experimental and the Control Groups obtained the pre-test during the first week which consists of 60 questions in three sections. Part one combines vocabulary with corresponding images (20 items). Part two in Bahasa Indonesia matches vocabulary with the related language (20 items). Part three fills up with English vocabulary (20 items) in the blank. This total of 60 English vocabulary items were taken from eight nursery rhymes and the vocabulary lists are organised to be. Starting from the second week to the ninth week the Experimental Group students were taught English vocabulary using nursery rhymes while the Control Group students were taught 70 minutes per week using traditional approach. Both groups were given the post-test during the tenth week to gauge their achievement in vocabulary mastering. The teacher, teaching the Experimental Group, used nursery rhymes and student-centered approach, while the instructor in the Control Group used traditional approaches using the teacher-centered approach, in which the instructor dominated the class hours. In that sense the students were likely to be the teacher's explanation's passive learners.

Before the actual study, a pilot test was conducted on 40 elementary school Third Grade students in Depok-Sleman, Yogyakarta, Indonesia, who have identical characteristics with the schools involved in this study. The pilot test aimed to determine the validity and reliability of the instruments used in this research. The pilot test results also suggested that the content, clarification and time allotted for the pre-test and the post-test were sufficient. Requesting two senior English teachers to check and assess the validity of the exam obtained the validity for the pre-test and the post-test.

\section{FINDINGS AND DISCUSION}

1. Ho1: There is no significance difference between the Experimental Group and the Control Group in their overall scores for vocabulary.

In the pre-test the overall mean scores for vocabulary of the Experimental Group is 19.43 while the Control Group has a mean score of 19.70. Findings from the independent samples ttest revealed that there is no significant difference between scores of the Experimental Group and the Control Group for their overall scores for vocabulary in the pre-test $(\mathrm{t}=-.445, \mathrm{df}=78$, p.145). 
Ipung Sri Purwanti Hery and Imran Arshad

Table 1 Comparing the mean of overall scores for vocabulary in the post-test

\begin{tabular}{lccccccc}
\hline \multicolumn{1}{c}{ Group } & N & Mean & SD & $\begin{array}{c}\text { Mean } \\
\text { Difference }\end{array}$ & t-value & Df & $\begin{array}{c}\text { P } \\
\text { value }\end{array}$ \\
\hline Experimental & 40 & 54.40 & 2.74 & 26.37 & 29.53 & 78 & .001 \\
Control & 40 & 28.03 & 4.94 & & & & \\
\hline
\end{tabular}

Significance is at $p<0$.

Tables 1 explains the overall mean scores for vocabulary in the post-test. The mean scores for the Experimental Group is 54.40 while the mean score of the Control Group is only 28.03. Findings from the independent samples t-test indicate that there is a significant difference between the mean scores of Experimental Group and Control Groups for After-test vocabulary mastery $(\mathrm{t}=29.529, \mathrm{df}=78, \mathrm{p}=.001)$. Hence the results do not recognise null hypothesis-1. These results indicate that the mean for overall vocabulary score for the Experimental Group is substantially higher than that for the Control Group.

The results clearly show that the use of nursery rhymes substantially increased overall vocabulary mastering scores for the Study Group relative to those students in the Control Group who were taught using the traditional method (teacher-centered approach). This result suggests that the use of nursery rhymes during the English class will help students develop their vocabulary awareness by connected to their schemas (prior knowledge) and this allows them to boost vocabulary mastering better than the Control Group.

This result fits with the theoretical concept underlying social constructivism (Vygotsky, 1978). This theory emphasised that the children learn from teachers and friends through observation, interaction, and scaffolding. Students observe the instructor through the use of songs, chants, and rhymes, communicate with each other, and practise orally that promote language development. Language plays a key role in mental growth and learning and the development occurs at the same time. The nursery rhymes are seen in this study as a central function in the mental growth that the students need to observe and communicate with each other when learning and link their actions to the vocabulary they are incorporated in the rhymes. For example, children learn brotherly relationship in one of the nursery rhymes entitled "Jack and Jill." Students hear how brother Jack and sister Jill went up the hill to help their mother get a pail of water out there. They worked hand in hand and unexpectedly Jack fell down and lost his crown and Jill came to help her brother tumbling after. They ran home and his mother tied brown paper to his back. Through this rhymes, students might imagine any moment, such as taking a pail of water up the hill, tumbling down and losing his crown. The moments gathered by the students from practising the rhymes allowed them to develop their vocabulary awareness by connected to their schemas. As a result, knowing and understanding the words will be easier because they have some knowledge with what the rhymes are telling; children also learn this as a result of social contact, this is important and facilitates the shift from oral to silent words (Garvey \& Hogan, 1973).

2. Ho2: There is no significance difference between the Experimental Group and the Control Group in their scores for matching the English vocabulary with the right picture.

In the pre-test the mean scores of the Experimental Group for matching the English vocabulary with the right picture is 6.90 , while the Control Group has a mean score of 6.85 . Findings from the Independent samples t-test revealed that there is no significance differences in the mean scores of the students in the Experimental and Control Groups for the vocabulary matching in the pre-test $(\mathrm{t}=.148 . \mathrm{df}=78, \mathrm{p}=.971)$. 
Using Nursery Rhymes to Enhance Vocabulary among Young English Learners in Indonesia

Table 2 Comparing of the mean scores for matching the vocabulary with the correct picture in the post-test

\begin{tabular}{lccccccc}
\hline \multicolumn{1}{c}{ Group } & N & Mean & SD & $\begin{array}{c}\text { Mean } \\
\text { Difference }\end{array}$ & t-value & Df & $\begin{array}{c}\text { P } \\
\text { value }\end{array}$ \\
\hline $\begin{array}{l}\text { Experimental } \\
\text { Control }\end{array}$ & 40 & 18.20 & 1.16 & 82.25 & 21.74 & 78 & .001 \\
\hline
\end{tabular}

Significance is at $p<0.05$

Table 2 demonstrates the mean scores in the post-test for matching the vocabulary with the correct picture. The Study Group's average scores are 18.20 while the Control Group's average score is just 9.98. Findings from the independent samples t-test revealed that there is a significance different between mean scores of the Experimental Group and Control Groups for the matching the vocabulary with the correct picture in the post-test $(\mathrm{t}=21.736, \mathrm{df}=78, \mathrm{p}=$ .001.). Hence the results do not recognise null hypothesis-2. These results indicate that the use of nursery rhymes substantially improved the performance of the Study Group as opposed to the Control Group.

The Experimental Community teacher used nursery rhymes and adopted a studentcentered approach to learning. This finding means that the use of nursery rhymes during the English class will help students develop their vocabulary awareness by triggering the schemas, enabling them to fit the vocabulary with the correct image.

The findings also align with the social-constructivist theory (Vygotsky), which Tracey and Morrow (2012) also support. This study concluded that: children learn language through contact with others, language development depends on sign systems, in order to learn new concepts one must work in the "field of proximal development," and learning support takes place through teachers' scaffolding and the peers enable the students to internalise and connect the new words to their existing scheme. For instance, when learning the "Hot Cross Buns" nursery rhyme, students perform such moments, such as, the man pushing his cart full of hot cross buns, giving a bun to a little girl and a boy; and the girl handed him a penny. Together the students were singing "Hot cross buns, one a penny two hot cross buns. If you don't have a daughter, give them a penny two a penny of hot cross buns. This rhymes helped students to internalise the happy moment while getting the buns. These sign systems gathered by the students singing the rhymes allowed them to enrich their established vocabulary. As a result, singing will make them feel more relaxed because they observed body gestures and singing the rhymes.

3. Ho3: There is no significance difference between the Experimental Group and the Control Group in their scores for matching English vocabulary with the appropriate meaning in Bahasa Indonesia.

In the pre-test, the mean scores for matching English vocabulary with the appropriate meaning in Bahasa Indonesia of the Experimental Group is 6.80 while the Control Group has a mean score of 7.00. Findings from the Independent samples t-test revealed that there is no significant difference between the mean scores of the Experimental Group and the Control Group for matching the English vocabulary with the appropriate meaning in Bahasa Indonesia in the pre-test $(\mathrm{t}=-.620, \mathrm{df}=78, \mathrm{p}=.568)$.

Table 3 Comparing the mean scores for matching the English vocabulary with the appropriate meanings in Bahasa Indonesia in the post-test

\begin{tabular}{lccccccc}
\hline \multicolumn{1}{c}{ Group } & N & Mean & SD & $\begin{array}{c}\text { Mean } \\
\text { Difference }\end{array}$ & t-value & Df & $\begin{array}{c}\text { P } \\
\text { value }\end{array}$ \\
\hline Experimental & 40 & 18.60 & 1.57 & 81.0 & 15.02 & 78 & -.000 \\
Control & 40 & 10.50 & 3.03 & & & & \\
\hline
\end{tabular}

Significance is at $p<0.05$ 
Table 3 displays the mean scores in post-test at Bahasa Indonesia for matching vocabulary with the relevant context. The Experimental Group's mean scores are 18.60 while Control Group's average score is 10.50. Findings from the Independent Samples t-test showed a substantial difference in post-test scores between the Experimental Group and the Control Groups $(\mathrm{t}=15,021, \mathrm{df}=78, \mathrm{p}=.000)$. Hence the results do not recognise null hypothesis-3. These results suggest that the use of nursery rhymes has helped the Experimental Group students understand the vocabulary better than the Control Group students.

Referring to the finding in table 3 , it is apparent that when students were taught using nursery rhymes their scores to fit the English vocabulary with the relevant context in Bahasa Indonesia significantly improved compared to the Control Group. These results suggest that using English-language nursery rhymes can help students enrich their English vocabulary skills relative to the control group that was taught using traditional methods.

That result correlates with the concrete learning theory of Ausubel (1963). He emphasised that effective learning happens when the learner incorporates and acquires new information into the existing knowledge systems that he / she has.

This process of assimilating new information with existing information fortifies a learner's knowledge structure. In this analysis, the nursery rhymes are seen as a meaningful material that incorporated new information into the related systems of prior knowledge that students have.

Initially, the nursery rhymes were introduced to the students through the storey and attracted their attention; the repetition of words in each rhythm and rhythm makes them learn new vocabulary using body movement to illustrate the new vocabulary, automatically making students understand and memorise the meaning of the words. For starters, the students were taught how to appreciate nature in "Itsy Bitsy Spider," and learned how to be a hard worker. The students were expected to practise imitating how a spider scaled a waterspout under the light of the sun and then the rain came down and the spider washed out. The sun shined and the rain water in the water spout dried up. This encouraged the spider to scale the water spout once more. This knowledge from which the students gathered orally while learning the nursery rhymes provides simple and unforgettable examples of new words and their significance. As a result, students will feel more comfortable learning English using the rhymes of the nursery as they contribute to their everyday lives.

4. Ho4: There is no substantial difference in their ratings between the Study Group and the Control Group for filling in the blanks with the required English vocabulary.

In the pre-test the mean scores for bank filling with the Experimental Group's right vocabulary are 5.73, while the Control Group scored just 5.85. Findings from the independent t-test analyses showed that there is no substantial difference between the Experimental Group scores and the Pre-test Control Groups $(\mathrm{t}=-357, \mathrm{df}=78, \mathrm{p}=.558)$.

Table 4 Comparing the mean score for filling in the blanks with correct vocabulary in the post-test

\begin{tabular}{lccccccc}
\hline \multicolumn{1}{c}{ Group } & N & Mean & SD & $\begin{array}{c}\text { Mean } \\
\text { Difference }\end{array}$ & t-value & Df & $\begin{array}{c}\text { P } \\
\text { value }\end{array}$ \\
\hline Experimental & 40 & 17.60 & 2.06 & 10.05 & 20.82 & 78 & -.378 \\
Control & 40 & 7.55 & 2.25 & & & \\
\hline
\end{tabular}

Significance is at $p<0.05$

Table 4 displays the mean after test scores for in the blanks with the required English vocabulary. The Experimental Group's mean scores are 17.60 while the Control Group's average score is 7.55. Findings from the independent samples t-test showed a substantial difference between the Experimental Group's mean scores and the Post-Test Control Groups for filling in the blanks with the required English vocabulary $(t=20.820, d f=78, p=-378)$. 
The results therefore refuse to recognise null hypothesis- 4 . These findings indicate that the use of nursery rhymes substantially improved the students' vocabulary scores in the Experimental Group relative to the control group that was taught using traditional approach.

Krashen's Affective Filter Hypothesis (1982) confirmed the observation. This theory notes that many affective variables including inspiration, self-confidence and anxiety promote second language learning. High motivation, high self-confidence and low anxiety promote learning, while low motivation, low self-esteem and high anxiety boost the affective barrier and build a mental block that prevents learning of languages. Furthermore, based on the observation of the researcher within this study during the intervention, nursery rhymes could lower the anxiety of the students. The students were inspired while chanting nursery rhymes. They developed their self-confidence by singing and dancing to learn the English vocabulary. In addition, elements of fun-learning in the teaching of nursery rhymes allow the Experimental Group students to master the vocabulary better than their counterparts in the Control Group.

\section{CONCLUSION}

This research has significant implications for teaching and learning English vocabulary in a classroom with a foreign language. Results show that the use of nursery rhymes is an important and alternative approach that teachers can employ to improve vocabulary mastery among young Indonesian English learners. This method is capable of improving the achievement of students in the overall scores of the Experimental Group in vocabulary acquisition in all three aspects, i.e.: matching vocabulary with the appropriate picture; matching vocabulary with the appropriate meaning in Bahasa Indonesia and filling the blanks with some terms provided in comparison with the students in the Control Group who were taught using the appropriate meaning However, the teacher is the key person responsible for organising and executing the group learning exercises during vocabulary learning in the classroom, in teaching nursery rhymes. As such teachers need to introduce the nursery rhymes by instruction and education on how to carry out the activities in the classrooms.

Students exposed to the system of nursery rhymes had many positive features and values such as empathy, ability to listen, cooperation and assistance among community members, accountability and self-confidence. The study finding also serves as a reference for the Ministry of Education to make the nursery rhymes system an important input for the innovation of English language teaching in elementary schools, in particular The Teachers ' Training Institution. The English teachers may use the modules (eight nursery rhymes) given by the researcher as models in their English classes. This would also improve comprehension of researchers, scholars and politicians by explaining the impact of nursery rhymes compared to traditional method of teaching. This study has some limitations as it includes only eighty students and two teachers as subjects, so more research using larger samples and different age ranges is necessary to establish the effects of using nursery rhymes in teaching vocabulary among young English learners in Indonesia. The researcher analysed only the quantitative data in this study. It is hoped that future research will also use qualitative data to explore the effects of using nursery rhymes to improve vocabulary among young English learners in Indonesia.

\section{REFERENCES}

[1] Ara, S. (2009). Use of songs, rhymes and games in teaching English to young learners in Bangladesh. Dhaka University Journal of Linguistics, 2 (3), 161-172.

[2] Arzal \& Tanipu, Z. (2014). Blending online language laboratory into Indonesian EFL listening classroom. Issues in Language Studies 3 (2), 1-9. 
[3] Atta-Alla, M. N. (2012). Developing Adult English language learners' vocabulary skills through children's rhymes and songs. English Language Teaching, 5(11), 79.

[4] Ausubel, D. P. (1962). A Subsumption theory of meaningful verbal learning and retention. The Journal of General Psychology, 66(2), 213-224.

[5] Bhatti, A., \& Akram, H. (2020). The Moderating Role Of Subjective Norms Between Online Shopping Behaviour And Its Determinants. International Journal of Social Sciences and Economic Review.

[6] Bhatti, A., Bano, T., \& Rehman, S.-U.-. (2019). Social Media and Consumer Satisfaction Effect on Consumer Purchase Intention with the Moderating Role of Trust International journal of Business Management, 4(2), 131-141.

[7] Bhatti, A., \& Rehman, S. U. (2019a). Impact of Social risk, Government and Psychological Factors with Moderator Cultural Factors on Online Shopping Behavior in Pakistan Pakistan Journal of Humanities and Social Sciences, 7(1), 31-44.

[8] Bhatti, A., \& Rehman, S. u. (2019b). Perceived Benefits and Perceived Risks Effect on Online Shopping Behavior with the Mediating Role of Consumer Purchase Intention in Pakistan. IJMS, 26(1), 33-54.

[9] Bhatti, A., Rehman, S. U., Akram, H., \& Shaheen, M. (2020). The role of Social Media, Advertising and Viral Marketing on Customer Satisfaction. International Journal of Advanced Science and Technology, 29(8s).

[10] Bloom, B. S. (1964). Stability and change in human characteristics. New York, 1.

[11] Boudreau, D. (2005). Use of a parent questionnaire in emergent and early literacy assessment of preschool children. Language, speech, and hearing services in schools, 36(1), 33-47.

[12] Brown, C. L. (2007). Strategies for making social studies texts more comprehensible for English-language learners. The Social Studies, 98(5), 185-188.

[13] Candlin, C. N. 1988. Preface. In R. Carter \& M. McCarthy (eds.), Vocabulary and Language Teaching. New York: Longman.

[14] Dunst, C. J., Meter, D., \& Hamby, D. W. (2011). Relationship between young children's nursery rhyme experiences and knowledge and phonological and print-related abilities. Center for Early Literacy Learning, 4(1).

[15] Enever, J., \& Moon, J. (2010). A global revolution? Teaching English at primary school. In $A$ British Council seminar delivered on November 5th.

[16] Er, S. (2014). Which is the most appropriate strategy for very young language learners?. International Journal of Social Sciences \& Education,4(4).

[17] Garvey, C., \& Hogan, R. (1973). Social speech and social interaction: Egocentrism revisited. Child Development, 562-568.

[18] Harper, L. J. (2011). Nursery rhyme knowledge and phonological awareness in preschool children. The Journal of Language and Literacy Education, 7(1), 63-78.

[19] Hart, B., \& Risley, T. R. (1995). Meaningful differences in the everyday experience of young American children. Paul H Brookes Publishing.

[20] Horst, M. (2014). Mainstreaming second language vocabulary acquisition. Canadian Journal of Applied Linguistics/Revue Canadienne de Linguistique Appliquée, 16(1), 171-188.

[21] Intani, E. N. (2012). Developing Modified Indonesian Children Song Lyrics To Teach Vocabulary To Elementary School Third Graders. English Education Journal, 2(2).

[22] Knight, S. (1994). Dictionary use while reading: The effects on comprehension and vocabulary acquisition for students of different verbal abilities. The Modern Language Journal, 78(3), 285-299. 
Using Nursery Rhymes to Enhance Vocabulary among Young English Learners in Indonesia

[23] Krashen, S. (1982). Principles and practice in second language acquisition (pp. 1982-1982). Pergamon: Oxford.

[24] Krashen, S. D. (1985). The input hypothesis: Issues and implications. Addison-Wesley Longman Ltd.

[25] Lamb, M. \& Coleman, H. (2008). Literacy in English and the Transformation of Self and Society in Post-Suharto Indonesia. International Journal of Bilingual Education and Bilingualism, 11/2, 189-205.

[26] Lamb, M. (2011). A Matthew Effect in English language education in a developing country context. In H. Coleman (Ed.). Dreams and realities: Developing countries and the English language (pp.186-206). Retrieved August 9, 2011, from: http://tinyurl.com/3hld6wl.

[27] Lamb, M. A. R. T. I. N. (2009). Situating the second language-self: Two Indonesian school learners of English. Motivation, language identity and the second language-self, 229-247.

[28] Maclean, M., Bryant, P., \& Bradley, L. (1987). Rhymes, nursery rhymes, and reading in early childhood. Merrill-Palmer Quarterly, 33, 255-281.

[29] Mehring, J. G. (2010). Developing vocabulary in second language acquisition: From theories to the classroom. Retrieved from http://172.22.23.2/pdoc/47/developvoc\% 20in\%202nd\%20lang\%20acquisiton.pdf.

[30] Milton, J. (2009). Measuring second language vocabulary acquisition (Vol. 45). Multilingual Matters.

[31] Musthafa, B. (2010). Teaching English to young learners in Indonesia: Essential requirements. Journal, 4(2).

[32] Nation, I. S. (2001). Learning vocabulary in another language. Ernst Klett Sprachen.

[33] Prihatin, P. N. (2012). The Computer Integration into the EFL Instruction in Indonesia: An Analysis of two University Instructors in Integrating Computer Technology into EFL Instruction to Encourage Students' Language Learning Engagement.

[34] Reyhner, J. (2003). The reading wars: Phonics versus whole language. Northern Arizona University. Kay: http://jan. ucc. nau. edu/ jar/Reading Wars. html.

[35] Sari, Y. L. (2008). Improving students 'pronunciation using nursery rhymes for the fifth grade students of SDN 03 Krajankulon Kaliwungu Kendal: An action research (Doctoral dissertation, Universitas Muhammadiyah Surakarta).

[36] Schiller, P. (2010). Songs and Rhymes as a Springboard to Literacy. Last retrieved on April 10,2015.http://www.earlychildhoodnews.com/earlychildhood/article_home.aspx?ArticleID=4 78.

[37] Schütz, R. (2007). Stephen Krashen's theory of second language acquisition. English made in Brazil, 2(2), 2007.

[38] Seargeant, P., \& Erling, E. J. (2011). The discourse of 'English as a language for international development': Policy assumptions and practical challenges. Dreams and Realities.

[39] Shwetha. R.,MA. (2013). Nursery Rhymes as an Effective Instructional Material for Young Language Learners. Language in India www.languageinindia.com ISSN 1930-2940.

[40] Sikki, E. A. A., Rahman, A., Hamra, A., \& Noni, N. (2013). The competence of primary school English teachers in Indonesia. Journal of Education and Practice, 4(11), 139-145.

[41] Stahl, S. A., \& Vancil, S. J. (1986). Discussion is what makes semantic maps work in vocabulary instruction. The Reading Teacher, 62-67.

[42] Tracey, D. H., \& Morrow, L. M. (2012). Lenses on reading: An introduction to theories and models. Guilford Press. 
[43] Vygotsky, L. S. (1978). Imagination and its development in childhood. The collected works of LS Vygotsky, 1, 339-350.

[44] Widyaningrum, A. (2011). Accelerating English proficiency for elementary school students through integrated skills. Jurnal Ilmiah Dinamika Bahasa dan Budaya, 5(1), 34-43.

[45] Yusuf, H. O., \& Enesi, A. O. (2012). Using sound in teaching reading in early childhood education. Journal of Language Teaching and Research, 3(4), 660-666.

[46] Yuwono, G. I., \& Harbon, L. (2010). English teacher professionalism and professional development: Some common issues in Indonesia. Asian EFL Journal, 12(3), 145-163. 